\title{
Reporting on Glucose Control Metrics in the Intensive Care Unit
}

\author{
Rafael Machado Tironi ${ }^{1}$ and Jean-Charles Preiser ${ }^{2}$
}

1. Registrar; 2. Professor, Department of Intensive Care, Erasme University Hospital, Universite libre de Bruxelles, Brussels, Belgium

\begin{abstract}
The 'diabetes of injury' typically associated with critical illness has recently been thoroughly revisited and much better characterised following major therapeutic advances. The occurrence of severe hyperglycaemia, moderate hypoglycaemia or high glycaemic variability has been associated with an increased mortality and rate of complications in large independent cohorts of acutely ill patients. Hence, current guidelines advocate the prevention and avoidance of each of these three dysglycaemic domains, and the use of a common metrics for a quantitative description of dysglycaemic events, such as the proportion of time spent in the target glycaemic range as a unifying variable. Using a common language will help to face the future challenges, including the definition of the most appropriate blood glucose (BG) target according to the category of admission, the time interval from the initial injury and the medical history. The clinical testing of technological improvements in the monitoring systems and the therapeutic algorithms should be assessed using the same metrics.
\end{abstract}

\section{Keywords}

Critically ill, stress hyperglycaemia, diabetes of injury, stress response, insulin, blood glucose, continuous glucose monitoring (CGM)

Disclosure: Rafael Machado Tironi and Jean-Charles Preiser have no conflicts of interest to declare. No funding was received for the publication of this article. Open Access: This article is published under the Creative Commons Attribution Noncommercial License, which permits any non-commercial use, distribution, adaptation and reproduction provided the original author(s) and source are given appropriate credit.

Received: 17 June 2015 Accepted: 16 July 2015 Citation: European Endocrinology, 2015;11(2):75-8 DOI: 10.17925/EE.2015.11.02.75

Correspondence: Jean-Charles Preiser, Department of Intensive Care, Erasme University Hospital, Universite libre de Bruxelles, 808 route de Lennik, B-1070 Brussels,

Belgium. E: jean-charles.preiser@erasme.ulb.ac.be

Acute illness is typically associated with the so-called 'stress-induced hyperglycaemia', defined as a transient hyperglycaemia in patients without previous evidence of diabetes. ${ }^{1}$ The strong relationship between stress hyperglycaemia and poor outcome is largely established and actually validates hyperglycaemia as a marker of illness severity.

The correction of a moderate stress hyperglycaemia may improve the prognosis. Indeed, in 2001, a large single-centre randomised controlled trial (RCT) in critically ill surgical patients demonstrated that tight glucose control (TGC) (defined as the restoration and maintenance of blood glucose [BG] concentration between 4.4 and $6.1 \mathrm{mmol} / \mathrm{l}$ [80 and 110 $\mathrm{mg} / \mathrm{l})$ by intensive insulin therapy (IIT) was associated with decreased mortality and rate of complications. ${ }^{2}$ However, subsequent studies performed in other intensive care units (ICUS) $)^{3-8}$ failed to reproduce the beneficial effects of IIT titrated to achieve TGC. ${ }^{9}$ The controversy that followed these conflicting results triggered a major interest in the physiopathology of stress response, resulting in important findings and a re-appraisal of the current knowledge.

This review intends to provide a brief summary of the current understanding of the toxicity of prolonged hyperglycaemia, the mechanisms underlying the three domains of dysglycaemia, that is, hyperglycaemia, hypoglycaemia and high glycaemic variability (GV), and the available clinical data from observational and interventional studies, and to outline some of the challenges for the future of the field.

\section{Prolonged Hyperglycaemia-associated Toxicity}

In stress conditions, an overall massive glucose overload happens in organs where glucose uptake is not regulated by insulin, usually quoted as non-insulin-mediated glucose uptake (NIMGU) tissues, under the influence of pro-inflammatory mediators, counterregulatory hormones, and hypoxia..$^{10}$ Hence, a wide range of tissues, including hepatocytes, endothelial cells, neurons, nephrons and immune cells, may be susceptible to enhanced glucose toxicity as a result of acute illness. Several deleterious effects have been associated with these high glucose concentrations in cells. ${ }^{1.11}$ Damage to mitochondrial proteins occurs and the formation of reactive oxygen species (ROS) is increased as a consequence of the shift from glycolysis towards accessory metabolic pathways (pentose phosphate, hexosamines, polyols).12 Other effects of excess glucose concentrations include the exacerbation of inflammatory pathways, decreased complement activity, modifications in the innate immune system, impairment in endothelial and hepatic mitochondrial functions and abolishment of the ischaemic preconditioning and protein glycosylation. Acute complications attributed to stress hyperglycaemia include renal failure, increased susceptibility to infections, polyneuropathy and impaired microcirculation.?

\section{Mechanisms Underlying the Three Domains of Dysglycaemia Hyperglycaemia}

Although sharing some similarities, the pathogenetic mechanisms of type 2 diabetes and stress hyperglycaemia are different (see Table 1). In diabetes, the cause of hyperglycaemia is a combination of insulin resistance and defective secretion of insulin by pancreatic $\beta$-cells. During stress hyperglycaemia, complex interactions between counterregulatory hormones (catecholamines, growth hormone, cortisol) and cytokines lead to an excessive and non-inhibitable production of glucose 


\section{Table 1: Main Differences between Type 2 Diabetes and Stress Hyperglycaemia}

\begin{tabular}{|c|c|c|}
\hline & Diabetes & Stress Hyperglycaemia \\
\hline Aetiology & $\begin{array}{l}\text { Combination of lifestyle } \\
\text { and genetic factors }\end{array}$ & $\begin{array}{l}\text { Secondary to trauma, surgery } \\
\text { or acute illness }\end{array}$ \\
\hline $\begin{array}{l}\text { Glycated } \\
\text { haemoglobin }\end{array}$ & $\begin{array}{l}\text { Elevated if poorly } \\
\text { controlled }\end{array}$ & Normal \\
\hline $\begin{array}{l}\text { Pathogenetic } \\
\text { mechanisms }\end{array}$ & $\begin{array}{l}\text { Insulin resistance } \\
\text { Defective secretion of } \\
\text { insulin (by pancreatic } \\
\beta \text {-cells) }\end{array}$ & $\begin{array}{l}\text { Interaction of regulatory } \\
\text { hormones, cytokines, production } \\
\text { of glucose by the liver } \\
\text { Insulin resistance (insulin-mediated } \\
\text { glucose uptake tissues) }\end{array}$ \\
\hline $\begin{array}{l}\text { Causes of } \\
\text { hypoglycaemic } \\
\text { episodes }\end{array}$ & $\begin{array}{l}\text { Oral medications } \\
\text { Insulin }\end{array}$ & $\begin{array}{l}\text { Insulin therapy } \\
\text { Interruption of carbohydrates } \\
\text { infusion } \\
\text { Severe sepsis, liver failure, } \\
\text { adrenal insufficiency }\end{array}$ \\
\hline Complications & $\begin{array}{l}\text { Micro- and macro- } \\
\text { angiopathy (renal, } \\
\text { cardiac, ocular, } \\
\text { cerebral and } \\
\text { neurological) }\end{array}$ & $\begin{array}{l}\text { Complications related to } 1^{\circ} \\
\text { condition causing } \\
\text { dysglycaemia }\end{array}$ \\
\hline Evolution & $\begin{array}{l}\text { Chronic } \\
\text { Not curable }\end{array}$ & $\begin{array}{l}\text { Can disappear after } \\
\text { resolution } \\
\text { of acute illness } \\
\text { Higher risk of developing } \\
\text { type } 2 \text { diabetes }\end{array}$ \\
\hline Treatment & $\begin{array}{l}\text { Lifestyle } \\
\text { Oral medications } \\
\text { Insulin (added to oral } \\
\text { medication when } \\
\text { insufficient) }\end{array}$ & $\begin{array}{l}\text { Treatment of underlying cause } \\
\text { Insulin therapy }\end{array}$ \\
\hline
\end{tabular}

IMGU: insulin-mediated glucose uptake.

associated with insulin resistance of the tissues where glucose uptake is insulin-dependent (IMGU), perhaps as an adaptive response needed to promote survival during the acute phase. ${ }^{10,13}$ Indeed, this highly complex interplay is largely variable over time. ${ }^{1,12}$

The stress-related increase in hepatic output of glucose results from glycogenolysis and gluconeogenesis. Glycogenolysis is primarily triggered by catecholamines and perpetuated under the influence of epinephrine and cortisol. Gluconeogenesis is triggered to a larger extent by glucagon than by epinephrine and cortisol. Among the numerous inflammatory mediators released in the acutely ill, tumour necrosis factor- $\alpha$ (TNF $\alpha$ ) might promote gluconeogenesis by stimulating glucagon production. The increase in peripheral resistance is characterised by the inability of skeletal muscles and adipocytes to take up glucose, related to an alteration of insulin signalling and a downregulation of type 4 glucose transporters (GLUT-4).

An increased glucose reabsorption or a decreased renal glucose clearance has also been reported and likely contributes to hyperglycaemia in acute conditions. ${ }^{14}$ In the post-operative patient, the surgical stress itself is an important trigger, via the induction of insulin resistance under the influence of cytokines and counterregulatory hormones. The degree of insulin resistance has been related to the magnitude and the duration of the surgical stress. The avoidance of hypothermia, excessive blood losses, prolonged pre-operative fasting period and prolonged immobilisation synergises to reduce perioperative insulin resistance.

\section{Hypoglycaemia}

Regardless of the underlying cause, hypoglycaemia is physiologically reversed counterregulatory mechanisms, activated in a stepwise manner. ${ }^{15,16}$ The successive steps include the inhibition of insulin secretion, followed by the release of glucagon, epinephrine, growth hormone and cortisol in cases of worsening hypoglycaemia. Glucagon will stimulate the production of glucose by glycogenolysis and gluconeogenesis at the liver, while epinephrine will help to increase BG by inhibiting glucose utilisation by several tissues and stimulating glycogenolysis and gluconeogenesis at the liver, acting via beta-2-adrenergic receptors. Cortisol and growth hormone will stimulate the hepatic glucose production.

These protective homeostatic mechanisms against hypoglycaemia are altered in patients with diabetes. Secretion of insulin is inexistent in patients with type 1 diabetes and diminished in type 2 diabetes, and the glucagon and epinephrine response to hypoglycaemia can be blunted. In the critically ill, hypoglycaemia can either occur spontaneously or can be induced by iatrogenic factors, such as interruption of infusion of a nutritional solution or insulin infusion. Spontaneous episodes of hypoglycaemia include end-stage liver failure and adrenal failure during septic shock. In these conditions the physiological response to hypoglycaemia is blunted. In case of iatrogenic episodes, the ability to increase the release of glucagon, epinephrine or cortisol can be impaired, in relation to the metabolic stress. Importantly, regardless of the underlying cause, hypoglycaemia is most often asymptomatic during critical illness, in relation to sedation and/or altered mental status.

\section{High Glycaemic Variability}

The complex mechanisms of BG regulation and homeostasis are altered in critically ill patients, especially during sepsis and after trauma and major surgery, as a result of the increased secretion of cytokines and hormones, ${ }^{17}$ which can alter the neural and hormonal physiological regulatory pathways of BG. In addition, treatment-related factors, such as the type and route of nutrition and insulin therapy, can also increase GV.

Regardless of its cause, high GV can negatively affect cellular function as a result of endothelial damage, ${ }^{18,19}$ or changes in serum osmolarity, which can affect cellular function. ${ }^{20,21}$ Although the precise mechanisms are mostly speculative and unknown, high GV is associated with a poor outcome during critical illness (see the next paragraph).

\section{Available Clinical Data Observational Studies}

Quite consistently, retrospective studies performed on large cohorts of different categories of critically ill patients reported poorer outcome of patients who experienced dysglycaemic events. However, the strength of the relationship between markers of dysglycaemia and outcome is variable according to the diabetic status. Overall, admission hyperglycaemia was found as an independent marker of mortality and morbidity. ${ }^{22-25}$ Patients with an average BG below $7.8 \mathrm{mmol} / \mathrm{l}$ $(<140 \mathrm{mg} / \mathrm{dl})$ was associated with a better outcome than those with a higher average BG. ${ }^{22-25}$

After cardiac surgery, the occurrence of hyperglycaemia above $10 \mathrm{mmol} / \mathrm{l}$ (180 mg/dl) was consistently and independently associated with a significant increase in both deep sternal wound infections and mortality. ${ }^{26-28}$

Likewise, the occurrence of hypoglycaemia represents an independent factor of mortality in critically ill patients. ${ }^{29-33}$ In contrast to former beliefs, even mild hypoglycaemia, defined as a BG $<4$ mmol/l $(80 \mathrm{mg} / \mathrm{dl})$ was 
Table 2: Examples of indices to Report When Studying Blood Glucose Control

$\begin{array}{llll}\text { Purpose of the Study } & \text { Central Tendency } & \text { Dispersion } & \text { Lowest Value } \\ \text { Association studies } & \text { Mean blood glucose } & \text { Standard deviation } & \text { Percentage of hypoglycaemia } \\ & \text { Admission blood glucose } & \text { Coefficient of variation } & \text { Rlycaemic lability index } \\ \text { Physiological investigations } & \text { Mean (daily) blood glucose } & \text { Mean amplitude of glycaemic excursions } & \text { Rate of hypoglycaemia } \\ & & \text { Maximal glucose changes } & \text { Patients with at least n episodes of hypoglycaemia } \\ \text { Quality/safety of care } & \begin{array}{l}\text { Proportion of blood glucose in target } \\ \text { Time in range }\end{array} & & \\ & \text { Delay to reach target } & & \end{array}$

Table 3: Glucose Metrics Reported in Large-Scale Studies

\begin{tabular}{|c|c|c|c|c|c|c|c|c|c|c|}
\hline & \multicolumn{5}{|c|}{ Central Tendency } & \multicolumn{4}{|c|}{ Dispersion Variability } & \multirow{2}{*}{$\begin{array}{l}\text { Minimal Value } \\
\text { Min }\end{array}$} \\
\hline & A & $T$ & $\mathrm{H}$ & $M$ & $\mathrm{M}$ & $S$ & C Range & Max & G & \\
\hline & v & A & 1 & $\mathrm{E}$ & $A$ & D & v & & L & \\
\hline & G & G & & D & G & & & & 1 & \\
\hline & & & & & E & & & & & \\
\hline Van den Berghe et al. ${ }^{2}$ & + & & & & & + & & & & + \\
\hline Van den Berghe et al. ${ }^{3}$ & + & & & & & + & & & & + \\
\hline Preiser et al. ${ }^{7}$ & & & & + & & & & & & + \\
\hline Falciglia et al. ${ }^{24}$ & + & & & & & & & & & \\
\hline Badawi et al. ${ }^{25}$ & & + & & & & & + & & & + \\
\hline Egi et al..$^{30}$ & + & & & & & + & & + & & \\
\hline Krinsley ${ }^{36}$ & & & & & & + & & & & + \\
\hline Donati et al. ${ }^{37}$ & & & & + & + & + & + & & + & \\
\hline Kosiborod et al. ${ }^{42}$ & + & + & + & & & & & & & \\
\hline Plummer et al. ${ }^{44}$ & & & + & + & & & & & & \\
\hline
\end{tabular}

Variables reported to characterise central tendency, dispersion/variability and minimal values. AVG = average; CV = Coefficient of variation (=SD/AVG); GLI = Glycemic Lability Index; $\mathrm{HI}=$ hyperg/ycaemic index; $\mathrm{MAGE}=$ mean amplitude of glycaemic excursions; $M E D=$ median; $S D=$ standard deviation; TAG = time-averaged glucose.

significantly associated with an increase of risk of mortality. ${ }^{30,31}$ Finally, the third dysglycaemic domain, high GV, has also been independently associated with increased mortality and morbidity. ${ }^{33-37}$ Importantly, the occurrence of several dysglycaemic events synergistically increased mortality. ${ }^{25,38}$

Comparing the relationship between dysglycaemia and outcome in critically ill patients with and without diabetes yielded interesting and consistent differences. Several studies consistently reported a flatter relationship or J-shaped curve between BG and mortality in diabetic than in non-diabetic patients. ${ }^{39-44}$

\section{Interventional Trials}

The first large landmark interventional $\mathrm{RCT}^{2}$ reported an impressive reduction in ICU mortality and in-hospital mortality of patients randomised to IIT. In the medical ICU of the same hospital, ${ }^{3}$ the survival benefit was restricted to the subset of long-stayers. The external validity of these studies and the optimal BG target were assessed in large single-centre and multiple-centre prospective trials of TGC by IIT comparing two ranges of BG. ${ }^{4-9}$ All trials aimed to compare the effects of insulin therapy, dosed to restore and maintain BG between 4.4 and $6.1 \mathrm{mmol} / \mathrm{l}(80-110 \mathrm{mg} / \mathrm{dl})$. Where they differed was in the target range of BG for the control (nonIIT) group. The Glucontrol ${ }^{7}$ and the Normoglycaemia in Intensive Care Evaluation-Survival Using Glucose Algorithm Regulation (NICE-SUGAR) ${ }^{8}$ trials used a target value of 7.8-10.0 mmol/l (140-180 mg/dl), while two Leuven studies, ${ }^{2,3}$ the Prospective randomised multicenter study on the influence of colloid versus crystalloid volume resuscitation and of IIT versus conventional insulin therapy on outcome in patients with severe sepsis and septic shock (VISEP) study, ${ }^{6}$ and two other single-centre largescale trials ${ }^{4,5}$ used a target value of 10-11.1 mmol// (180-200 mg/dl).

\section{Figure 1: Traces of Blood Glucose Values}

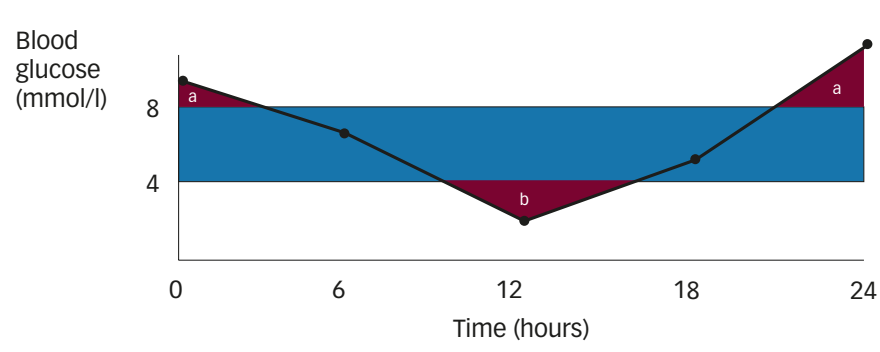

Blood
glucose $(\mathrm{mmol} / \mathrm{l})$

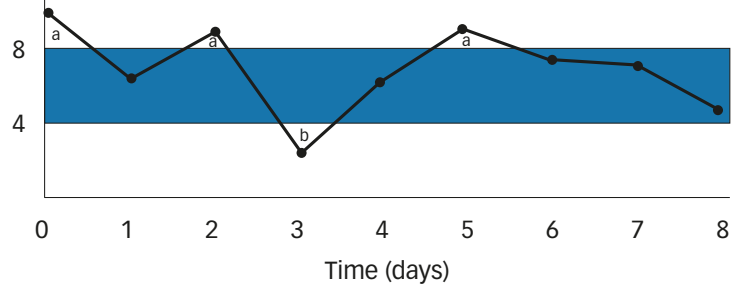

Blue rectangle represents the target area. Top panel: values recorded over a 24-h period; bottom panel: values recorded over an 8-day period. Zones a: hyperglycaemic indices, zones b: hypoglycaemic indices. The time in rangeTIR can be calculated as the total area minus hyper- and hypoglycaemic indices.

In the largest of these trials, the NICE-SUGAR study, IIT was associated with an increase in 90-day mortality, while in the other confirmatory trials, no difference in the outcome of the two groups was found. As expected, IIT was associated with a four- to sixfold increase in the incidence of hypoglycaemia (reported in $5-25 \%$ of the patients randomised to IIT). This high incidence of hypoglycaemia represents the major concern when starting IIT. 


\section{Diabetes}

Based on these observational and interventional data, the current guidelines from various scientific bodies consistently recommend maintaining the $B G$ below $10 \mathrm{mmol} / \mathrm{l}(180 \mathrm{mg} / \mathrm{dl})$, to prevent hypoglycaemia, even moderate, and to minimise GV ${ }^{45-47}$

\section{Challenges for the Future}

In 2015, several factors in the field of glucose control have been clarified, whereas others are still unsolved. Among the points agreed by the community of intensivists, the concept of three domains of dysglycaemia has been widely accepted. However, a universal agreement of the definitions used to characterise the three domains is still lacking. Examples of indices are shown in Table 2, and variables reported by some studies are listed in Table 3. A recent consensus from a board of experts recommended that any study in the field should at least report one index of central tendency and dispersion and minimal BG value. ${ }^{48}$ In practical terms, the performance of any ICU and/or of any change in the therapeutic strategy (new algorithm, new meter, and new target) should be assessed in respect to these three domains. The metrics used can differ according to the purpose of the report (see Table 2).

Time in range (TIR) can be considered as a unifying metrics. ${ }^{39,49-51}$ It can be calculated either on a daily basis or for the entire length of stay (see Figure 1). This index summarises the proportion of time spent within the target range and can be calculated from intermittent or continuous BG values; however, using intermittent data implies a linear interpolation of values between two successive readings. The relevance of TIR has been confirmed in association studies on large cohorts of patients, where a higher TIR was associated with a better vital outcome. ${ }^{39,5}$

The use of a common language will probably improve the relevance of future clinical trials designed to address unsolved matters, including the most appropriate BG target according to the category of admission, the time interval from the initial injury and the medical history. For instance, a patient with poorly equilibrated type 2 diabetes could tolerate higher BG than a non-diabetic patient. Likewise, the achievement of a low BG value could be more risky in a brain-injured patient than in other categories, owing to the detrimental effects of hypoglycaemia in case of brain injury. The amount and type of nutrition can also influence the optimal BG target. A meta-analysis of the seven large-scale prospective trials on TGC by IIT revealed that among various possible factors, only the delivery of a high ( $>80 \%$ ) proportion of calories by the parenteral route was associated with an improvement in hospital mortality of patients randomised to IIT. ${ }^{9}$

\section{Conclusions}

A consistent, clear association between dysglycaemia and poor outcome is present in critically ill patients. These findings support the current recommendation of liberal glucose control by insulin, i.e. in view of the risks associated with tighter therapeutic strategies. The use of consistent indices of the three domains of dysglycaemia is required to delineate the optimal BG target in different categories of patients and the logistical requirements for a safe and reliable glucose control and to assess technical advances that could improve the quality and safety of glucose control.
1. Dungan KM, Braithwaite SS, Preiser JC, Stress hyperglycaemia, Lancet, 2009;23:1798-807.

2. Van den Berghe G, Wouters P, Weekers F, et al., Intensive insulin therapy in the critically ill patients, N Eng/ J Med, 2001;345:1359-67.

3. Van den Berghe G, Wilmer A, Hermans G, et al., Intensive insulin therapy in the medical ICU, N Eng/ J Med, 2006;3545:449-61.

4. Arabi YM, Dabbagh OC, Tamin HM, et al., Intensive versus conventional insulin therapy: a randomized controlled trial in medical and surgical critically ill patients, Crit Care Med, 2008:36:3190-7.

5. De la Rosa GC, Donado JH, Restrepo AH, et al., Strict glycaemic control in patients hospitalized in a mixed medical glycaemic control in patients hospitalized in a mixed medica
and surgical intensive care unit: a randomized clinical trial, and surgical intensive Care

6. Brunkhorst FM, Engel C, Bloos F, et al., Intensive insulin therapy and pentastarch resuscitation in severe sepsis? N Eng/ I Med, 2008;358:125-39.

7. Preiser JC, Devos P, Ruiz-Santana S, et al., A prospective randomised multi-centre controlled trial on tight glucose control by intensive insulin therapy in adult intensive care units: the Glucontrol study, Intensive Care Med, 2009;35:1738-48.

8. NICE-SUGAR Study Investigators, Finfer S, Chittock DR, et al Intensive versus conventional glucose control in critically patients, N Engl J Med, 2009;360:1283-97.

9. Marik P, Preiser JC, Toward understanding tight glycemic control in the ICU: a systematic review and metaanalysis, Chest, 2010;137:544-51.

10. Lena D, Kalfon P, Preiser JC, Ichai C, Glycemic control in the intensive care unit and during the postoperative period, Anesthesiology, 2011:114:438-44.

11. Brownlee $\mathrm{M}$, Biochemistry and molecular cell biology of diabetic complications, Nature, 2001;414:813-20.

12. Bagry HS, Raghavendran S, Carli F, Metabolic syndrome and insulin resistance. Perioperative considerations, Anesthesiology, 2008;108:506-23.

13. Marik PE, Bellomo R, Stress hyperglycemia: an essentia survival response, Crit Care, 2013;17:305.

14. Sicardi SZ, Rodhe P, Hahn G, Progressive decrease in glucose clearance during surgery, Acta Anaesthesiol Scand 2006;50:848-54.

15. Cryer PE, Mechanisms of sympathoadrenal failure and hypoglycemia in diabetes, J Clin Invest, 2006;116:1470-3.

16. Lacherade JC, Jacqueminet S, Preiser JC, An overview of hypoglycemia in the critically ill, Diabetes Sci Technol, 2009:3:1242-9.

17. Preiser JC, Ichai C, Orban JC, Groeneveld AB, Metabolic response to the stress of critical illness, Br J Anaesth, 2014;113:945-54.

18. Risso A, Mercury F, Quagliaro L, et al., Intermittent hig glucose enhances apoptosis in human umbilical vein endothelial cells in culture, Am J Physiol Endocrinol Metab, 2001;281:E924-30
19. Collier B, Dossett LA, May AK, Diaz JJ, Glucose control and the inflammatory response, Nutr Clin Pract, 2008:23:3-15.

20. Otto NM, Schindler R, Lun A, et al., Hyperosmotic stress enhances cytokine production and decreases phagocytosis in vitro, Crit Care, 2008;12:R107.

21. Van den Berghe $G$, Schoonheydt $K$, BecX $P$, et al., Insulin therapy protects the central and peripheral nervous system of intensive care patients, Neurology, 2005;64:1348-53.

22. Krinsley JS, Effect of an intensive glucose management protocol on the mortality of critically ill adult patients, Mayo Clin Proc, 2004;79:992-1000.

23. Finney SJ, Zekveld C, Elia A, Evans TW, Glucose control and mortality in critically ill patients, JAMA, 2003:290:2041-7.

24. Falciglia M, Freyberg RW, Almenoff PL, et al., Hyperglycemiarelated mortality in critically ill patients varies with admission diagnosis, Crit Care Med, 2009:37:1-9.

25. Badawi $\mathrm{O}$, Waite MD, Fuhrman SA, Zuckerman $\mathrm{IH}$, Association between intensive care unit-acquired dysglycemia and in-hospital mortality, Crit Care Med, 2012;40:3180-8.

26. Furnary AP, Wu Y, Eliminating the diabetic disadvantage: the Portland Diabetic Project, Semin Thor Cardiovasc Surg 2006;18:302-8.

27. D'Alessandro C, Leprince P, Golmard JL, et al., Strict glycemic control reduces EuroSCORE expected mortality in diabetic patients undergoing myocardial revascularization, I Thorac Cardiovasc Surg, 2007; 134:29-37.

28. Ouattara A, Lecompte P, Le Manach Y, et al., Poor intraoperative blood glucose control is associated with a worsened hospital outcome after cardiac surgery in diabetic patients, Anesthesiology, 2005;103:687-94.

29. NICE-SUGAR Study Investigators, Hypoglycemia and risk of death in critically ill patients, N Eng/ J Med, 2012;367:1108-18.

30. Egi M, Bellomo R, Stachowski E, et al., Hypoglycemia and outcome in critically ill patients, Mayo Clin Proc, 2010;85:217-24.

31. Krinsley JS, Schultz MJ, Spronk PE, et al., Mild hypoglycemia is independently associated with increased mortality in the critically ill, Crit Care, 2011;15:R173.

32. Vriesendorp TM, van Santen S, DeVries JH, et al., Predisposing factors for hypoglycemia in the intensive care unit, Crit Care Med, 2006;34:96-101.

33. Arabi YM, Tamim HM, Rishu AH, Hypoglycemia with intensive insulin therapy in critically ill patients: predisposing factors and association with mortality, Crit Care Med, 2009:37:2536-44.

34. Egi M, Bellomo R, Stachowski E, et al., Variability of blood glucose concentration and short-term mortality in critically ill glucose concentration and short-term mortalty
patients, Anesthesiology, 2006;105:244-52.

35. Dossett $L A$, Cao H, Mowery NT, et al., Blood glucose variability is associated with mortality in the surgical intensive care unit, Ann Surg, 2008;74:679-8

36. Krinsley JS, Glycemic variability: a strong independent predictor of mortality in critically ill patients, Crit Care Med, 2008;36:3008-13.
37. Donati A, Damiani E, Domizi R, et al., Glycaemic variability, infections and mortality in a medical-surgical intensive care unit. Crit Care Resusc, 2014;16:13-23.

38. Mackenzie I, Whitehouse T, Nightingale P, The metrics of glycaemic control in critical care, Intensive Care Med, 2011;37:435-43.

39. Krinsley JS, Preiser JC, Time in blood glucose range 70 to $140 \mathrm{mg} / \mathrm{dl}>80 \%$ is strongly associated with increased survival in non-diabetic critically ill adults, Crit care, 2015;19:179.

40. Egi M, Bellomo R, Stachowski E, et al., Blood glucose concentration and outcome of critical illness: the impact of diabetes, Crit Care Med, 2008;36:2249-55.

41. Rady MY, Johnson DJ, Patel BM, et al., Influence of individua characteristics on outcome of glycemic control in intensive care unit patients with or without diabetes mellitus, Mayo care unit patients with or with
Clin Proc, 2005:80:1558-67.

42. Kosiborod M, Rathore SS, Inzucchi SE, et al., Admissio glucose and mortality in elderly patients hospitalized with acute myocardial infarction: implications for patients with and without recognized diabetes, Circulation, 2005; 111:3078-86

43. Van den Berghe G, Wilmer A, Milants I, et al., Intensive insulin therapy in mixed medical/surgical intensive care units: benefit versus harm, Diabetes, 2006;55:3151-9.

44. Plummer MP, Bellomo R, Cousins CE, et al., Dysglycaemia in the critically ill and the interaction of chronic and acute glycaemia with mortality, Intensive Care Med, 2014;40:973-80.

45. Moghissi SE, Korythowski MT, DiNardo M, et al., American Association of clinical endocrinologists and American Diabetes Association consensus statement on inpatient Diabetes Association consensus statement on
glycaemic control, Endocr Pract, 2009;15:1-17.

46. Ichai C, Preiser JC, On behalf of the Steering Committee, the Expert panel, International recommendations for glucose control in adult non diabetic critically ill patients, Crit Care, 2010;14:R166

. Jacobi J, Bircher N, Krinsley J, et al., Guidelines for the use of an insulin infusion for the management of hyperglycemia in critically ill patients, Crit Care Med, 2012;40:3251-76.

48. Finfer S, Wernerman J, Preiser JC, et al., Clinical review: consensus recommendations on measurement of blood glucose and reporting glycemic control in critically ill adults, Crit Care, 2013;17:229.

49. Eslami $S$, de Keizer NF, de Jonge $E$, et al., A systematic review on quality indicators for tight glycaemic control in critically
ill patients: need for an unambiguous indicator reference ill patients: need for an unambig
subset, Crit Care, 2008:12:R139.

50. Penning S, Chase JG, Preiser JC, et al., Does the achievement of an intermediate glycemic target reduce organ failure and mortality? A post hoc analysis of the Glucontrol trial, J Crit Care, 2014;29:374-9

51. Penning S, Pretty C, Preiser JC, et al., Glucose control positively influences patient outcome: a retrospective study, J Crit Care, 2015;30:455-9. 